\title{
Genetic gain and relationship of yield and yield attributes of mutant and cross-bred stevia (Stevia rebaudiana) genotypes
}

\author{
SUSENO AMIEN ${ }^{1, \boldsymbol{v}}$, HARIS MAULANA ${ }^{1}$, DEDI RUSWANDI ${ }^{1}$, SARIFAH NURJANAH $^{2}$ \\ ${ }^{1}$ Faculty of Agriculture, Universitas Padjadjaran. Jl. Raya Bandung-Sumedang Km. 21, Jatinangor, Sumedang 45363, West Java, Indonesia. \\ Tel.: +62-22-84288842, Fax.: +62-22-84288843, ^email: suseno@unpad.ac.id \\ ${ }^{2}$ Faculty of Industrial Technology of Agriculture, Universitas Padjadjaran. Jl. Raya Bandung-Sumedang Km. 21, Jatinangor, Sumedang 45363, West \\ Java, Indonesia
}

Manuscript received: 25 May 2021. Revision accepted: 7 July 2021.

\begin{abstract}
Amien S, Maulana H, Ruswandi D, Nurjanah S. 2021. Genetic gain and relationship of yield and yield attributes of mutant and cross-bred stevia (Stevia rebaudiana) genotypes. Biodiversitas 22: 3119-3126. Plant breeding programs involved many traits and genetic parameters in the selection process. The information on genetic parameters on yield and other related traits provided an overview for breeders and farmers in selecting new superior genotypes. The purpose of this study was to estimate genetic parameters including heritability and genetic gains in yield and other traits, to determine the relationship between various traits, and to select superior stevia (Stevia rebaudiana Bertoni) genotypes for each trait. Field experiments were carried out in two planting environments, namely, the highlands and the medium plains employing a randomized completed block design and each genotype was three replicates. The results showed that the yield had high heritability and genetic gains in mutant populations, whereas cross-bred populations had moderate heritability and low genetic gains. Stem weight (SW) and number of leaves (NoL) traits were identified as having high heritability and genetic gains in both populations. The GT biplot measurement showed that the yield was identified to have a significant and positive correlation with SW ( $\mathrm{p}<0.05)$. H4 was correlated with Number of branches (NoB), Yield, SW, and chlorophyll content (Chl) traits in the cross-bred populations. H9 excelled on and was correlated with NoL and plant height (PH). M11 was identified to be highly correlated with $\mathrm{NoL}, \mathrm{PH}, \mathrm{NoB}$, and Chl traits in the mutant populations, while M15 excelled on and was correlated with yield and SW. The results of this study revealed that there was a potential for improvement in the traits tested of stevia through cross-bred and mutant populations in different environmental conditions. The selected genotypes can be developed in a suitable environment and used for further stevia plant breeding programs.
\end{abstract}

Keywords: GT biplot, heritability, selection, stevia, traits, West Java

\section{INTRODUCTION}

Stevia (Stevia rebaudiana Bertoni) is one of the potential sweetener plants. Stevia leaf have a higher sweetness than sugar (glucose) (Zhang and Bell 2017). In addition, the sweetness of stevia leaf also provides no side effects, so it is safe for consumption. Stevia leaf extract also has antibacterial, antifungal, antimicrobial, and antiviral properties (Kumar et al. 2014). Stevia has a yield potential of up to $60-80$ tons $\mathrm{ha}^{-1}$ annually. Stevia yields were influenced by altitude, temperature, day length, and photoperiod intensity (Benhmimou et al. 2017). In addition, pinching treatment has also been reported to increase stevia yields (Kumar et al. 2014). The description shows that stevia has the potential to be used as a source of natural sweetener that is safe for health with a fairly high yield and profit potential.

Selection is an important stage in plant breeding programs in determining superior genotypes. Several researchers have selected several characters including Yan and Frégeau-reid (2018) on oat yield, agronomic and quality traits, and Karuniawan et al. (2021) on the yield and sweetness traits of sweet potatoes. Selection on multiple traits allows researchers and farmers to select genotypes that excel at multiple traits. Therefore, this process will determine whether the genotype is further employed in the plant breeding program or not.

In developing new varieties, the genetic parameters including heritability and genetic gains are very important to determine the effect of additive genes. According to Annicchiarico et al. (2010), high heritability showed that the effect of additive genes in these traits was more dominant, so that the selection process for these traits can be carried out based on their phenotypic traits. Atnaf et al. (2017) added that if the heritability and genetic gains were low, then the environment influence was greater than the effect of additive genes. So that the selection process becomes less efficient. This suggests that high heritability and genetic gains were desirable in the plant selection process.

The development of superior plants with high yielding and other important traits is difficult and complicated. Many external factors influence it, including the emergence of the GE interactions (Maulana et al. 2020; Mustamu et al. 2018). The use of multiple traits can increase the efficiency of plant breeding programs. However, it is very difficult to do considering the large interaction between each trait against environmental factors. Currently, there is a genotype by traits (GT) biplot analysis to assess genotypes based on several traits and to identify superior genotypes based on several traits tested. Researchers used this 
measurement to understand the effect of genotype and environment on the relationship between yield and other traits (Yan and Frégeau-reid 2018). However, this measurement can only see the relationship between each trait and the yield, but cannot determine the effect of the combined yield on the other traits under different environmental conditions. Therefore, this measurement is very suitable for selecting genotypes that were superior to certain traits.

Information regarding yield and other traits of stevia genotypes is considerable. So far, some researchers have focused on growth and yield (Gomes et al. 2018; Kumar et al. 2014). However, some have identified other traits such as stevioside (Zhang and Bell 2017; Sieminska et al. 2020) and yield attributes (Benhmimou et al. 2017). Meanwhile, testing and selection of new stevia varieties for multi-traits are still very limited. The use of the GT biplot in this study was expected to add information about superior stevia genotypes in yields and other traits and estimate the relationship between each trait tested to be used for future stevia development and plant breeding programs.

\section{MATERIALS AND METHODS}

\section{Field trial and samples collection}

Field experiments were carried out in the highlands (Ciwidey, Bandung, Indonesia) and the medium plains (Jatinangor, Sumedang, Indonesia) using a randomized completed block design and three replicates. Ciwidey is at a coordinate of $7^{\circ} 05^{\prime} 34.8$ "South latitude, $107^{\circ} 29^{\prime} 07.8^{\prime \prime}$ East longitude, an altitude of $1100 \mathrm{~m}$ asl, an average temperature of $22^{\circ} \mathrm{C}$, average monthly rainfall $369.80 \mathrm{~mm}$, and average humidity during the experiment was $69 \%$. Jatinangor is at a coordinate of $6^{\circ} 54^{\prime} 59.6$ " South latitude $107^{\circ} 46^{\prime} 14.5^{\prime \prime}$ East longitude, an altitude of $530 \mathrm{~m}$ asl, an average temperature of $25.00^{\circ} \mathrm{C}$, an average monthly rainfall of $275.30 \mathrm{~mm}$, and average humidity during the experiment of $64 \%$. Each stevia genotype was planted at a distance of $50 \mathrm{~cm} \times 50 \mathrm{~cm}$. Each genotype was planted in three rows with 10 plants in each row. Information about the genotypes used was presented in Table 1. The traits observed in this study were yield, chlorophyll content (Chl), number of leaves (NoL), number of branches (NoB), plant height $(\mathrm{PH})$, and stem weight $(\mathrm{SW})$.

Table 1. New stevia genotypes used in the experiments

\begin{tabular}{|c|c|c|c|}
\hline Population & Codes & Genotypes & Information of the population \\
\hline \multirow[t]{16}{*}{ Mutant } & M1 & GR 3,5 B & Garut gama ray radiation 3,5 no. $B$ \\
\hline & M2 & TEA & Tawangmangu EMS no. A \\
\hline & M3 & GR 7,5 A & Garut gama ray radiation 7,5 no. A \\
\hline & M4 & TR $3,5 \mathrm{~B}$ & Tawangmangu gama ray radiation 3,5 no. B \\
\hline & M5 & $\mathrm{BEB}$ & Bogor EMS no. B \\
\hline & M6 & GR 5 B & Garut gama ray radiation 5 no. B \\
\hline & M7 & BR 5 B & Bogor gama ray radiation 5 no. B \\
\hline & M8 & GEA & Garut EMS no. A \\
\hline & M9 & BED & Bogor EMS no. D \\
\hline & M10 & TR 3,5 C & Tawangmangu gama ray radiation 3,5 no. $\mathrm{C}$ \\
\hline & M11 & BR 5 C & Bogor gama ray radiation 5 no. $\mathrm{C}$ \\
\hline & M12 & GR 3,5 C & Garut gama ray radiation 3,5 no. $\mathrm{C}$ \\
\hline & M13 & GR 7,5 B & Garut gama ray radiation 7,5 no. $B$ \\
\hline & M14 & TED & Tawangmangu EMS no. D \\
\hline & M15 & BR 5 D & Bogor gama ray radiation 5 no. D \\
\hline & M16 & BR $5 \mathrm{~A}$ & Bogor gama ray radiation 5 no. A \\
\hline \multirow[t]{12}{*}{ Cross-bred } & H1 & STG 1 & Tawangmangu x Garut 1 \\
\hline & $\mathrm{H} 2$ & STG 7 & Tawangmangu x Garut 7 \\
\hline & H3 & STG 8 & Tawangmangu x Garut 8 \\
\hline & $\mathrm{H} 4$ & STG 10 & Tawangmangu x Garut 10 \\
\hline & H5 & SBG 3 & Bogor x Garut 3 \\
\hline & H6 & SBG 4 & Bogor x Garut4 \\
\hline & $\mathrm{H} 7$ & SBG 5 & Bogor x Garut 5 \\
\hline & H8 & SBG 7 & Bogor x Garut 7 \\
\hline & H9 & SBG 10 & Bogor x Garut 10 \\
\hline & $\mathrm{H} 10$ & SGB 2 & Garut x Bogor 2 \\
\hline & H11 & SGB 3 & Garut $\mathrm{x}$ Bogor 3 \\
\hline & $\mathrm{H} 12$ & SBT 11 & Bogor x Tawangmangu 11 \\
\hline \multirow[t]{3}{*}{ Check } & $\mathrm{C} 1$ & BK & Bogor (Check) \\
\hline & $\mathrm{C} 2$ & TK & Tawangmangu (check) \\
\hline & $\mathrm{C} 3$ & GKA & Garut control (check) no. A \\
\hline
\end{tabular}




\section{Analysis of heritability and genetic gains}

Phenotypic and genotypic variance coefficients, heritability, genetic gains as percent of mean, were estimated following the formula by Fehr (1991):

$$
\begin{aligned}
& \text { Phenotypic varience coef ficient }=\frac{\sqrt{\delta_{p}^{2}}}{x} \times 100 \\
& \text { Genotypic varience coefficient }=\frac{\sqrt{\delta_{g}^{2}}}{x} \times 100 \\
& \delta_{p}=\sqrt{\delta_{p}^{2}} \\
& h^{2}=\frac{\delta_{g}^{2}}{\delta_{p}^{2}} \\
& \text { Genetic gains }=h^{2} \cdot i \cdot \delta_{p}
\end{aligned}
$$

Where, $\sigma_{\mathrm{p}}^{2}$ is phenotypic variance, $\sigma_{\mathrm{g}}^{2}$ is genotypic variance, $x$ is the grand mean; $h^{2}$ is the broad-sense heritability; $\sigma_{\mathrm{p}}$ is phenotypic standard deviation; and $i$ is the selection intensity $(20 \%=1.74)$. The heritability values were categorized as follows : $0-0.3$ as low, $0.3-0.6$ as moderate, and $>0.6$ as high. The values of genetic gains were categorized as follows: $0-10 \%$ as low, $10-20 \%$ as moderate, and $>20 \%$ as high (Johnson et al. 1955).

\section{Analysis of genotype by traits (GT) biplot}

The GT biplot analysis was used to determine each trait's relationship and select the best stevia genotypes based on each trait. The equations used to follow (Yan and Rajcan 2002):

$$
\frac{T_{i j}-T_{j}}{s j}=\lambda_{1} \zeta_{i 1} \tau_{j 1}+\lambda_{2} \zeta_{i 2} \tau_{j 2}+\varepsilon_{i j}
$$

Where, $T_{i j}$ is the average of $\mathrm{i}^{\text {th }}$ genotype for $\mathrm{j}^{\text {th }}$ trait, $T_{j}$ is the average of $\mathrm{j}^{\text {th }}$ trait in all genotypes, $s j$ is the standard deviation of $\mathrm{j}^{\text {th }}$ trait among the genotype averages; $\zeta_{\mathrm{i} 1}$ and $\zeta_{\mathrm{i} 2}$ were the first and second principal component $(\mathrm{PC} 1$ and
PC2) scores for $\mathrm{i}^{\text {th }}$ genotype, $\tau_{\mathrm{J} 1}$ and $\tau_{\mathrm{J} 2}$ were the PC1 and PC2 scores for $\mathrm{j}^{\text {th }}$ trait, respectively, and $\varepsilon_{\mathrm{ij}}$ is the error of the model associated with the $\mathrm{i}^{\text {th }}$ genotype and $\mathrm{j}^{\text {th }}$ trait.

\section{The relationship analysis between each trait}

The relationship between each tested trait was calculated based on the Pearson correlation. The equations used was as follows:

$$
r_{x y}=\frac{\sum_{i=1}^{n} x_{i} y_{i}-\sum_{i=1}^{n} x_{i} \sum_{i=1}^{n} y_{i}}{\sqrt{\sum_{i=1}^{n} x_{i}^{2}-\left(\sum_{i=1}^{n} x_{i}\right)^{2}} \sqrt{\sum_{i=1}^{n} y_{i}^{2}-\left(\sum_{i=1}^{n} y_{i}\right)^{2}}}
$$

where $r_{x y}$ is the correlation coefficient. $x$ is the variable (trait) $x$, (and $y$ is the variable (trait) $y$. If the value is 1 or -1 , then the relationship is very strong. Meanwhile, if the value is close to 0.0 , then the relationship of the two variables is getting weaker.

GT biplot was analyzed using Genstat $12^{\text {th }}$ software, while the correlation between each trait was analyzed using Ms. Excel 2013.

\section{RESULTS AND DISCUSSION}

\section{Estimate of variance component, heritability, and genetic gains}

The coefficient of phenotypic variance $\left(\sigma^{2} p\right)$ was higher than the coefficient of genotypic variance $\left(\sigma^{2} \mathrm{~g}\right)$ for all traits studied in the two populations (Table 2). The difference between $\sigma^{2} \mathrm{p}$ and $\sigma^{2} \mathrm{~g}$ was taken into account in the environmental conditions in which the genotype grows. The wide difference between $\sigma^{2} \mathrm{p}$ and $\sigma^{2} \mathrm{~g}$ indicates a high

\begin{tabular}{|c|c|c|c|c|c|c|c|}
\hline Traits & Minimum & Mean & Maximum & $\sigma_{p}^{2}$ & $\sigma_{g}^{2}$ & $\mathbf{h}^{2}$ & Genetic gain $(\%)$ \\
\hline \multicolumn{8}{|c|}{ Mutant populations } \\
\hline Yield & 10.58 & 20.88 & 33.78 & 11.48 & 8.39 & 0.73 & 21.54 \\
\hline Stem weight (SW) & 4.90 & 15.72 & 36.35 & 10.85 & 8.58 & 0.79 & 22.66 \\
\hline Number of leaves (NoL) & 10.17 & 38.61 & 89.17 & 102.31 & 86.75 & 0.85 & 74.62 \\
\hline Number of branches (NoB) & 0.83 & 7.10 & 17.33 & 5.79 & 2.92 & 0.50 & 10.55 \\
\hline Plant height (PH) & 6.63 & 18.55 & 29.47 & 11.62 & 6.78 & 0.58 & 17.29 \\
\hline Chlorophyll content (Chl) & 11.51 & 24.20 & 35.87 & 9.78 & 5.99 & 0.61 & 16.66 \\
\hline \multicolumn{8}{|c|}{ Cross-bred populations } \\
\hline Yield & 7.77 & 20.24 & 29.20 & 5.12 & 2.02 & 0.40 & 9.73 \\
\hline Stem weight (SW) & 6.34 & 15.90 & 27.33 & 7.90 & 5.63 & 0.71 & 21.78 \\
\hline Number of leaves (NoL) & 17.00 & 45.63 & 89.17 & 65.44 & 49.89 & 0.76 & 67.06 \\
\hline Number of branches (NoB) & 1.83 & 8.47 & 17.33 & 3.38 & 0.51 & 0.15 & 3.03 \\
\hline Plant height $(\mathrm{PH})$ & 9.67 & 20.18 & 30.12 & 10.02 & 5.17 & 0.52 & 17.77 \\
\hline Chlorophyll content (Chl) & 11.54 & 23.61 & 35.28 & 9.04 & 5.25 & 0.58 & 18.99 \\
\hline
\end{tabular}
degree of environmental influence on these traits. In the mutants, the differences ranged from 2.27 at SW to 15.56 at NoL, indicated that environmental influences were significant on the expression of NoL; the same result was also shown by cross-bred population (cross-breeds).

Table 2. Coefficient of variance, heritability, and genetic gain on new stevia genotypes

Note: $\sigma_{\mathrm{p}}^{2}$ : coefficient of phenotypic variance; $\sigma_{\mathrm{g}}^{2}$ c coefficient of genotypic variance; $\mathrm{h}^{2}$ : broad-sense heritability 


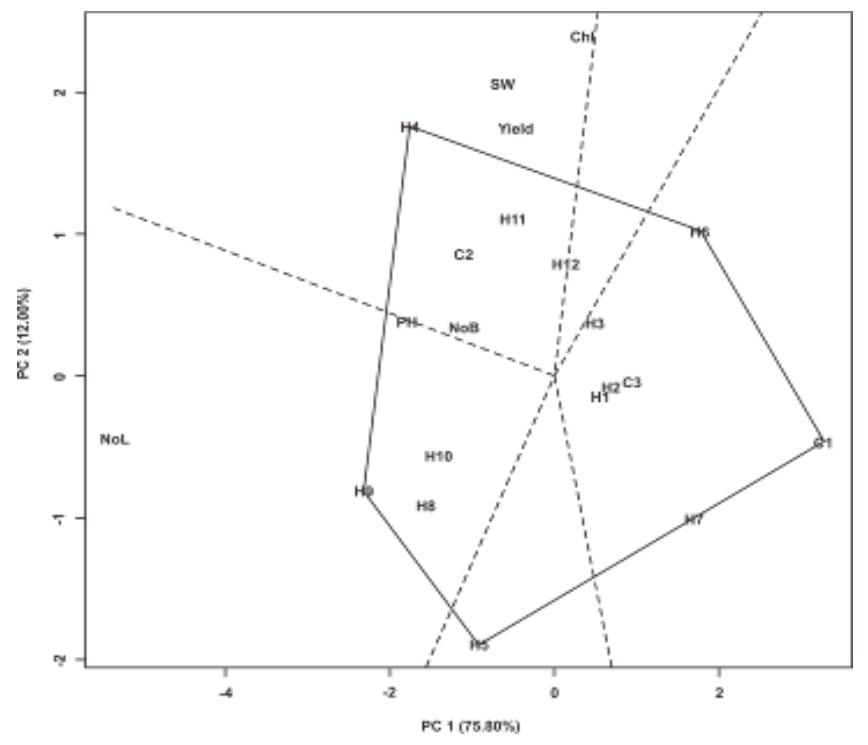

Figure 1. GT biplot "which, won, where" on the cross-bred populations into six traits. SW: stem weight; NoL: number of leaves; NoB: number of branches; PH: plant height; Chl: chlorophyll content

Based on Table 2, heritability estimates ranged from 0.50 for $\mathrm{PH}$ to 0.85 for yield in the mutant population. In the cross-bred population, it ranged from 0.15 for $\mathrm{NoB}$ to 0.76 for NoL. From the traits studied, SW and NoL consistently showed high heritability in both populations. Yield showed moderate to high heritability for both populations. NoB showed low to moderate heritability, $\mathrm{PH}$ showed moderate heritability in both populations, and Chl showed moderate to high heritability. The low heritability for NoB in cross-bred populations suggests that environmental factors were greater than genetic factors.

The high estimates of genetic gains were shown by the SW and NoL traits for both populations. Yield and NoB show low genetic gains in cross-bred populations and high in mutant populations. $\mathrm{PH}$ and $\mathrm{Chl}$ indicate moderate genetic gains in both populations.

\section{Relationships between traits tested against cross-bred and mutant populations of stevia using genotype by traits (GT) biplot}

Figure 1 shows the GT biplot "which won where" for cross-bred populations based on data from two planting environments. Five sectors were generated in Figure 1, with the genotypes and traits tested in different sectors. The genotypes in the same sector as the tested trait had a close relationship. $\mathrm{H} 4$ was in sector 1 and correlated with the NoB, Yield, SW, and Chl traits. H9 excelled in sector 2 which correlated with NoL and $\mathrm{PH}$. The test results also showed that the biplot was very strong because it represents $87.80 \%$ (PC1 and $\mathrm{PC} 2$ ) of the total variation.

Figure 2 shows the GT biplot "which won where" for mutant populations based on data from two planting environments. This population also produced five sectors that divided the genotypes and observed traits in different groups. Mutant M11 correlated with the NoL, PH, NoB,

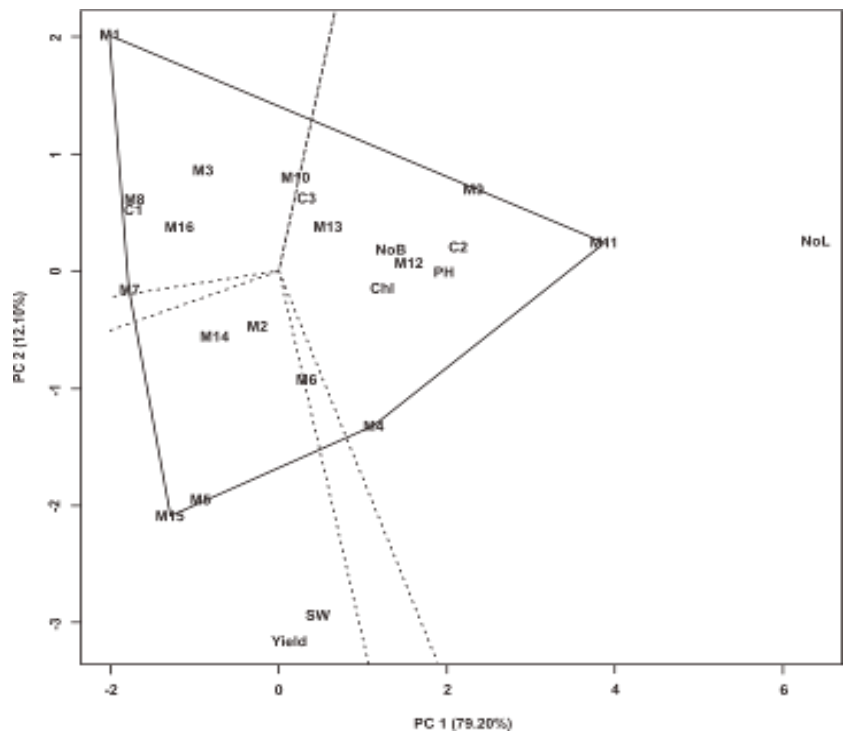

Figure 2. GT biplot "which, won, where" on the mutant populations into six traits. SW: stem weight; NoL: number of leaves; NoB: number of branches; PH: plant height; Chl: chlorophyll content

and Chl traits. M15 and M6 correlated with yield and SW. Figure 2 also shows that the biplot was very strong because it represents $91.30 \%$ of the total variation. In this study, both cross-bred and mutant populations, Check 1 (C1) was identified to be located apart from all traits measured. While the other two checks were still relationship to some of the observed traits. This indicates that check 1 (C1) has a relatively small value for all the traits being measured.

The relationship between the traits tested was presented in Table 3. Figure 3 and Figure 4 show the relationship between traits based on the GT biplot for cross-bred and mutant populations. Traits that have an acute angle $\left(<90^{\circ}\right)$ were stated to be positively correlated (have a close relationship), and vice versa. In cross-bred populations, yield has a very significant and positive correlation with SW, and had no significant correlation with other traits (Figure 3). Neither were the mutant populations (Figure 4). This explanation can be seen in the correlation value for each trait (Table 3 ). Table 3 shows that several other traits were positively and significantly correlated $(\mathrm{p}<0.05)$, i.e., NoL to NoB and $\mathrm{PH}$; and NoB with $\mathrm{PH}$ in cross-bred populations. In the mutant populations, NoL was significantly and positively correlated with $\mathrm{NoB}, \mathrm{PH}$, and Chl; while NoB was correlated with $\mathrm{PH}$.

Figure 3 also shows the ideal point, namely the arrow tip, which allows evaluation of the genotypes tested according to their proximity or distance to this center. The genotype that has closest to this point is the most ideal. According to Figure 3, C2 is more ideal than other genotypes because it was to closest to the "ideal center", while $\mathrm{C} 1, \mathrm{H} 5$, and $\mathrm{H} 7$ were the least desirable genotypes because they were located farthest from the "ideal center". In mutant populations, M4 was identified to be close to the "ideal center", while M1 followed by M8 and C1 were the farthest from this point (Figure 4). 


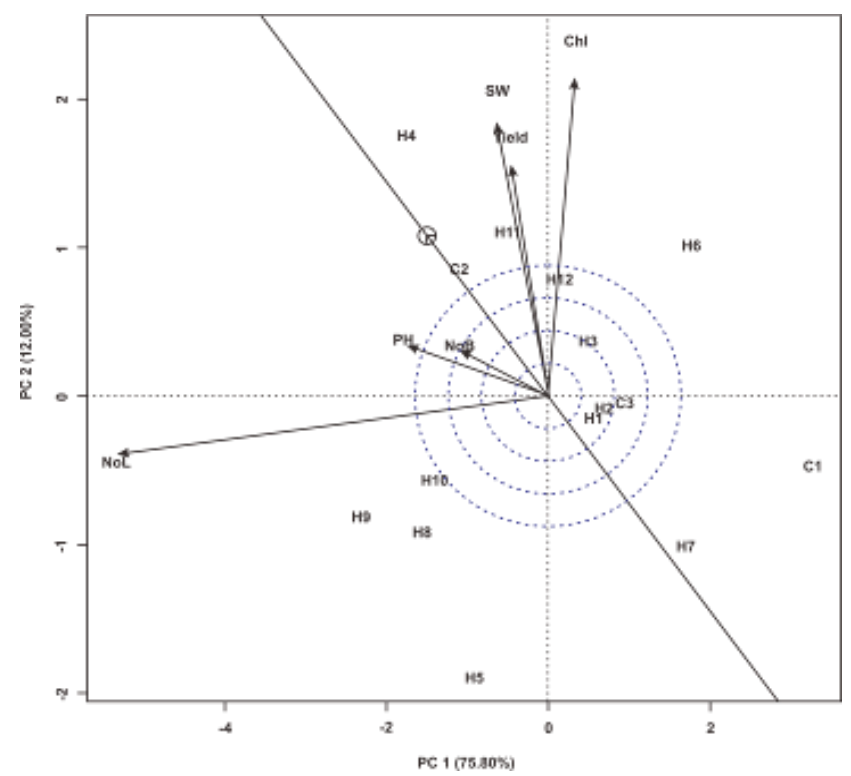

Figure 3. GT biplot "representativeness vs discriminativeness" on the cross-bred populations into six traits. SW: stem weight; NoL: number of leaves; NoB: number of branches; PH: plant height; Chl: chlorophyll content

Figures 5 and 6 show the axis of stability (Horizontal) and the average (vertical) axis based on the value of the traits tested. The genotypes that were above the vertical line (in the direction of the arrow in the small circle), are the expected genotypes. On the other hand, the genotype adjacent to the horizontal line is stable, and vice versa. In cross-bred genotypes, $\mathrm{C} 2, \mathrm{H} 4$, and $\mathrm{H} 11$ were quite stable and most preferred because they were located close to the horizontal axis, and located above the vertical axis (Figure 5). Meanwhile, M4 was identified as the most stable for all the traits tested in the mutant populations. M3 and M16 were close to the horizontal line, but they were far from the arrow in the small circle, so they have lower scores than the overall average.

\section{Discussion}

The yield and yield attributes are important traits in the breeding of new varieties. These traits were quantitative characters that are strongly influenced by the environment (Andrade et al. 2016). The study results showed that yield and Chl produced moderate to high heritability values for both populations. SW and NoL traits showed high heritability values in both populations. NoB showed low to high heritability, while $\mathrm{PH}$ showed moderate heritability in both populations. Some researchers also reported that yield and yield attributes have high heritability (Annicchiarico et al. 2010; Atnaf et al. 2017). The high heritability values indicated a high proportion of genetic diversity that can be passed on to the next generation. Thus, it can be used to select superior genotypes based on their phenotypic appearance (Alves et al. 2020; Annicchiarico et al. 2010; Atnaf et al. 2017). The high heritability value indicated that the genetic effects were greater than environmental effects on the observed variability.

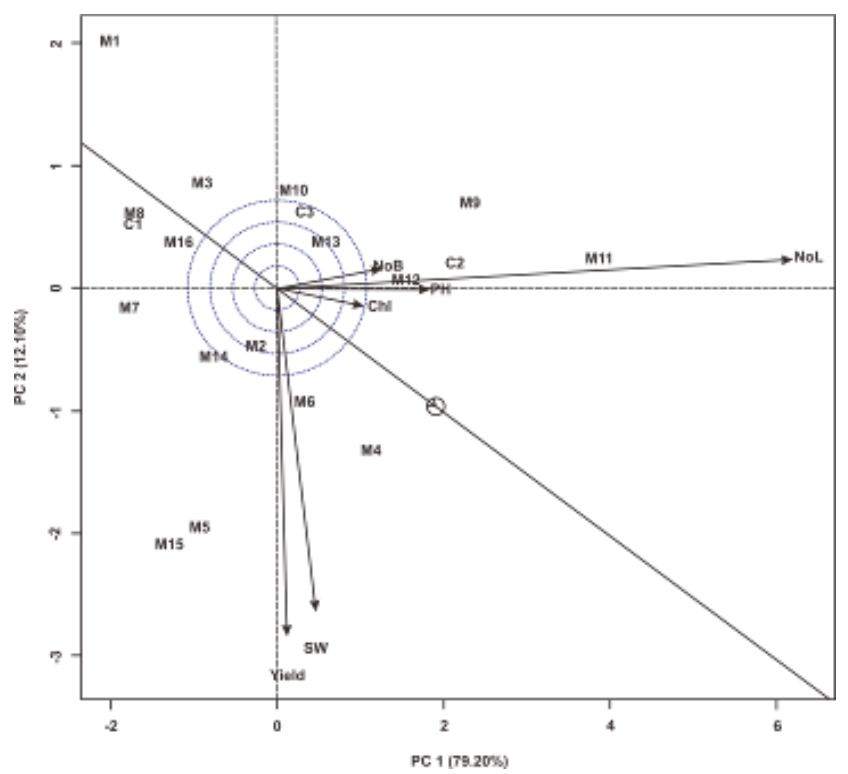

Figure 4. GT biplot "representativeness vs discriminativeness" on the mutant populations into six traits. SW: stem weight; NoL: number of leafes; NoB: number of branches; $\mathrm{PH}$ : plant height; Chl: chlorophyll content

The genetic gains measured indicated that the SW and NoL traits had high criteria for both populations. Annicchiarico et al. (2010) suggested that to predict superior genotype, considerations of heritability must be combined with genetic gains in the tested traits. High heritability coupled with high genetic gains indicated the additive gene effects, whereas high heritability coupled with low genetic gains indicated non-additive gene effects (Atnaf et al. 2017; Nehe et al. 2019; Sudrajat et al. 2018). The yield had high heritability and genetic gains in the mutant population, but the cross-bred population had moderate heritability and low genetic gains. SW and NoL had high heritability and genetic gains values in both populations. NoB had high heritability and genetic gains in the mutant population, but low value in the cross-bred population. While $\mathrm{PH}$ had moderate heritability and genetic gain values in all populations. Chl in the mutant population had high heritability but moderate genetic gain, while in the cross-bred population both heritability and genetic gains were moderate. Thus, the high criteria for genetic variance coefficient $\left(\sigma^{2} \mathrm{~g}\right)$, heritability, and genetic gains of yields in the mutant population indicated that there was greater additive gene action in regulating trait expression, so that the expected genetic of yield through selection was high. Meanwhile, estimates of high or moderate heritability values and low genetic gains indicated the presence of nonadditive gene action or genotypic interactions with the environment in the expression of these traits. This would make it difficult to plant selections for the improvement of the measured traits (Annichiaricho 2010). Some researchers also reported similar results for soybean mutants (Malek et al. 2014), mung beans (Payasi 2015), rice beans (Pandey et al. 2015), and white lupin (Atnaf et al. 2017). 


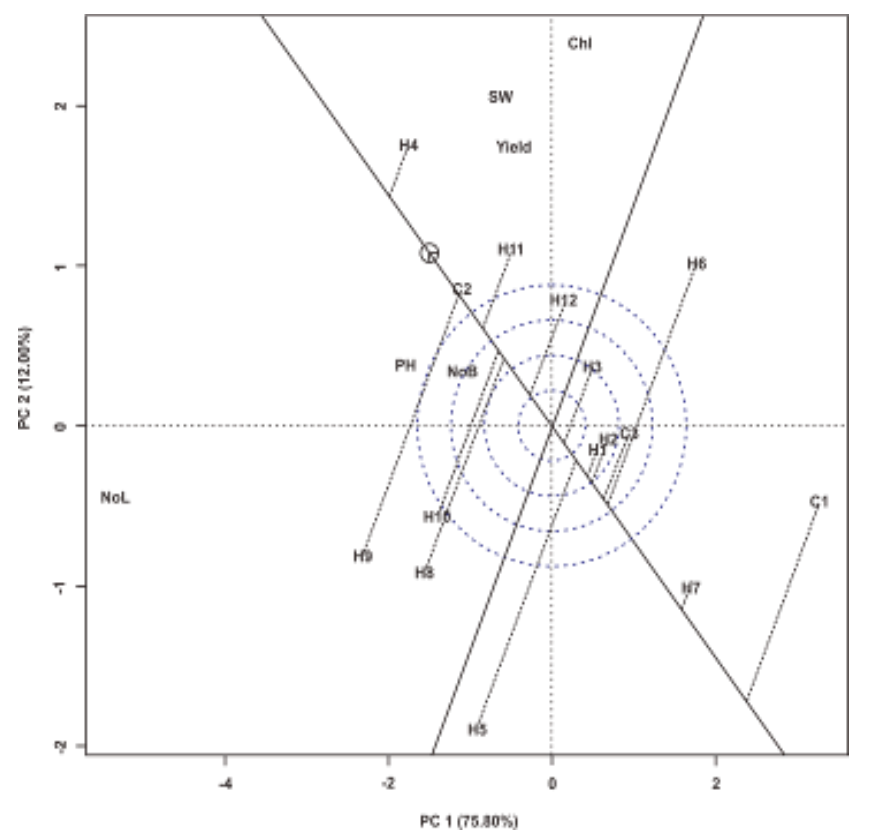

Figure 5. GT biplot "mean vs stability" on the cross-bred populations into six traits. SW: stem weight; NoL: number of leaves; NoB: number of branches; PH: plant height; Chl: chlorophyll content

The results showed that chlorophyll content is one of the properties that were influenced by the environmental factor. Chlorophyll content is one of the main components in the plant photosynthesis process. Chlorophyll content had a positive relationship with the rate of photosynthesis (Yeganehpoor et al. 2016). According to some researchers, the change of chlorophyll content in leaves was one of plant response to drought, to minimize light absorption by chloroplasts (Anjum et al. 2011; Ucar et al. 2018; Abrar et al. 2020). In addition, the other research stated that chlorophyll content changed can be also caused by increased environmental pressure, especially drought and salinity (Taïbi et al. 2016; Bertoldo et al. 2018; Ma et al. 2020). Anjum et al. (2011) added that decreased chlorophyll content under drought stress was a type of symptom of oxidative stress and chlorophyll degradation. In this study, there was no drought stress from the two environments, and the average rainfall was relatively high and uniform, so there was no significant decrease or increase in chlorophyll content.

The genotype by traits (GT) biplot analysis assesses the genotypes tested based on several traits and can identify superior genotypes based on the traits tested. The GT biplot was used to compare genotypes based on the trait tested. This technique can only estimate the relationship between each trait and yield, but can't determine the effect of combined yields on other traits under different environmental conditions (Yan and Frégeau-reid 2018;

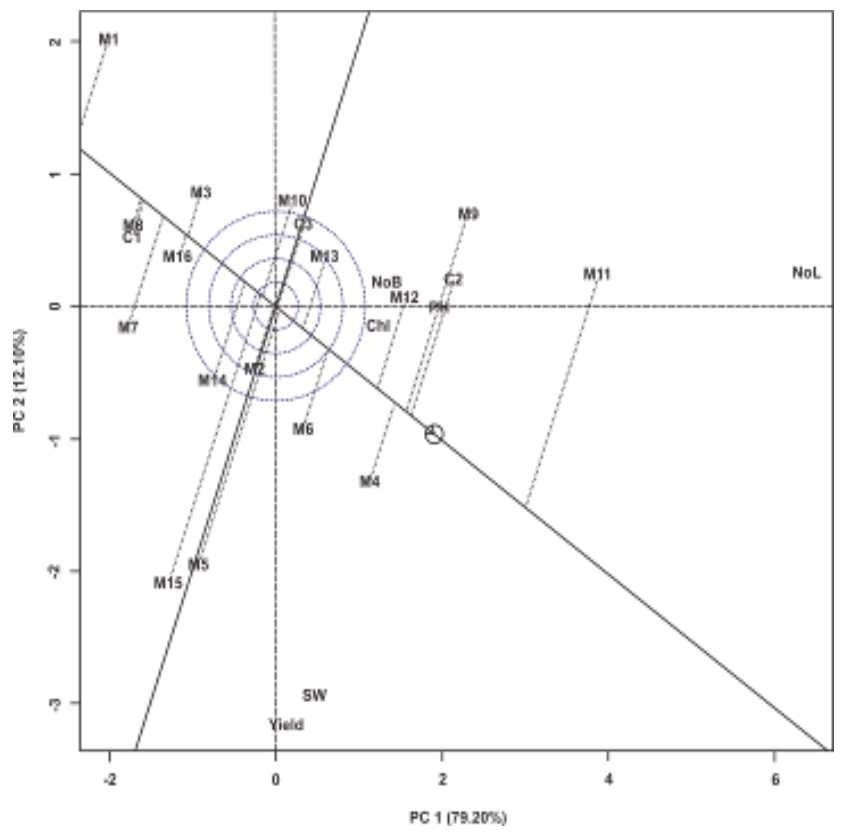

Figure 6. GT biplot "mean vs stability" on the mutant populations into six traits. SW: stem weight; NoL: number of leaves; NoB: number of branches; $\mathrm{PH}$ : plant height; Chl: chlorophyll content

Kendal 2019). The GT biplot analysis of the stevia genotypes showed very strong results as they were represented $87.80 \%$ for hybrids and $91.30 \%$ for mutants of the total variation. Kendal (2019) reported that the GT biplot analysis on wheat resulted in $61.50 \%$ of the total variation (quite strong). This showed that the results of the GT biplot on yields and other traits in the stevia genotypes in West Java are very good.

In cross-bred populations (Figure 1), H4 was the highest and correlated with the NoB, Yield, SW, and Chl traits. H9 had the highest and was correlated with NoL and $\mathrm{PH}$ as compared to other genotypes. In mutant populations (Figure 2), M11 was identified as the best genotypes for NoL, PH, NoB, and Chl traits. M15 and M6 were correlated with and identified as the best genotypes for yield and SW. The genotypes that were at the top of the sector were the best in the sector (Yan and Frégeau-reid 2018; Mohammadi 2019). Some studies revealed that quantitative traits are very difficult to predict because they were strongly influenced by environmental factors (Andrade et al. 2016; Ruswandi et al. 2020). In addition, genotype testing in more diverse environmental conditions was also needed to predict the favorable environments for each genotype, both mutant and cross-bred. So that testing of genotypes in a variety of environments and different seasons was needed to predict the adaptability of each genotype. 
Table 3. Pearson correlation between traits tested in stevia genotypes

\begin{tabular}{|c|c|c|c|c|c|c|}
\hline Traits & Yield & SW & NoL & NoB & PH & Chl \\
\hline \multicolumn{7}{|c|}{ Cross-bred populations } \\
\hline Yield & 1 & & & & & \\
\hline SW & $0.61 *$ & 1 & & & & \\
\hline NoL & 0.26 & 0.28 & 1 & & & \\
\hline $\mathrm{NoB}$ & 0.40 & 0.37 & $0.88 *$ & 1 & & \\
\hline $\mathrm{PH}$ & 0.29 & 0.39 & $0.80 *$ & $0.80 *$ & 1 & \\
\hline Chl & 0.30 & 0.14 & -0.17 & 0.01 & -0.12 & 1 \\
\hline \multicolumn{7}{|c|}{ Mutant populations } \\
\hline Yield & 1 & & & & & \\
\hline SW & $0.67 *$ & 1 & & & & \\
\hline NoL & 0.04 & 0.19 & 1 & & & \\
\hline NoB & -0.05 & 0.18 & $0.86 *$ & 1 & & \\
\hline $\mathrm{PH}$ & -0.01 & 0.27 & $0.90 *$ & $0.82 *$ & 1 & \\
\hline Chl & 0.04 & 0.17 & $0.59 *$ & 0.44 & 0.49 & 1 \\
\hline
\end{tabular}

Note: *significantly correlated at 5\% (p<0.05); SW: stem weight; NoL: number of leaf; NoB: number of branch; PH: plant heigh; Chl: chlorophyll content

In the GT biplot, yields were significantly correlated with SW because they had very sharp angles and were close to each other. In addition, the correlation analysis of the two traits was also strong $(0.61$ in cross-bred and 0.67 in mutants). This indicates that these two traits have a quite strong relationship. Meanwhile, other traits were correlated with each other (Figure 3 and Figure 4). Yan and Frégeaureid (2018) revealed that vector lines that have an angle of $<90^{\circ}$ show a significant and positive correlation. In addition, in Figure 5 and Figure 6 the tested genotypes were divided by vertical (average) and horizontal (stability) lines. The expected genotypes were above the vertical line and adjacent to the horizontal line, and the ideal genotypes were close to the ideal point (Abakemal et al. 2016; Kendal 2019). Currently, plant breeding program doesn't just refer to high yields. However, it has other advantages such as high and stable yields (Maulana et al. 2020), and has other good qualities and agronomic traits (Kendal 2019). In the study, C2 (in cross-bred populations) and M4 (in mutant populations) were identified to be close to the ideal point. So that the genotypes have yields and also traits that exceed the average value for each of the traits tested.

In conclusion, heritability and genetic gains of yield and other traits showed varied values. Yields have high heritability and genetic gains in mutant populations, whereas cross-bred populations have moderate heritability and low genetic gains. SW and NoL traits were identified as having high heritability and genetic gains in both populations. The results of the GT biplot measurement showed that the yield was identified to have a significant and positive correlation with SW. In the cross-bred populations, H4 was correlated with and superior for the NoB, Yield, SW, and Chl traits. H9 excelled on and was correlated with $\mathrm{NoL}$ and $\mathrm{PH}$. In the mutant populations, M11 was identified to be more correlated with NoL, PH, NoB, and Chl traits, while M15 excelled on and was correlated with yield and SW. The genotypes selected based on each trait can be used in future development and plant breeding programs. In addition, it was necessary to carry out tests on more varied environmental conditions to estimate the relationship and yield stability and other traits into environmental changes.

\section{ACKNOWLEDGEMENTS}

This research was funded by 'Penelitian Terapan', Ministry of Research, Technology and Higher Education (Republic of Indonesia) year 2019/2020. The authors declare that they have no conflict of interest

\section{REFERENCES}

Abakemal D, Shimelis H, Derera J. 2016. Genotype-by-environment interaction and yield stability of quality protein maize hybrids developed from tropical-highland adapted inbred lines. Euphytica 209 (3): 757-769. DOI: 10.1007/s10681-016-1673-7.

Abrar MM, Saqib M, Abbas G, Atiq-Urrahman M, Mustafa A, Shah SAA, Mehmood K, Maitlo AA, Mahmood-Ul-hassan, Sun N, Xu M. 2020. Evaluating the contribution of growth, physiological, and ionic components towards salinity and drought stress tolerance in Jatropha curcas. Plants 9 (11): 1574. DOI: 10.3390/plants9111574.

Alves NB, Balestre M, Pennacchi JP, Fernandes MCN, Castro DG, Botelho FBS. 2020. Genetic progress of upland rice (Oryza sativa L.) lines for disease resistance. Plant Breed 139 (5): 853-861. DOI: $10.1111 /$ pbr.12829.

Andrade MI, Naico A, Ricardo J, Eyzaguirre R, Makunde GS, Ortiz R, Gruneberg WJ. 2016. Genotype $x$ environment interaction and selection for drought adaptation in sweet potato (Ipomoea batatas [L.] Lam.) in Mozambique. Euphytica 209: 261-280. DOI: 10.1007/s10681-016-1684-4.

Anjum SA, Xie X, Wang L, Saleem MF, Man C, Lei W. 2011. Morphological, physiological and biochemical responses of plants to drought stress. Afr J Agric Res 6 (9): 2026-2032. DOI: 10.5897/AJAR10.027.

Annicchiarico P, Harzic N, Carroni AM. 2010. Adaptation, diversity, and exploitation of global white lupin (Lupinus albus L.) landrace genetic resources. Field Crops Res 119 (1): 114-124. DOI: 10.1016/j.fcr.2010.06.022. 
Atnaf M, Tesfaye K, Dagne K, Wegary D. 2017. Genotype by trait biplot analysis to study associations and profiles of Ethiopian white lupin (Lupinus albus L.) landraces. Austr J Crop Sci 11 (1): 55-62. DOI: 10.21475/ajcs.2017.11.01.pne226.

Benhmimou A, Ibriz M, Faïz CA, Gaboun F, Douaik A, Amchra FZ, Khiraoui A, Lage M. 2017. Effects of planting density and harvesting time on productivity of natural sweetener plant (Stevia rebaudiana Bertoni.) in Larache Region, Morocco. Int J Plant Res 7 (4): 83-89. DOI: 10.5923/j.plant.20170704.01.

Bertoldo E, Siega TDC, Nicareta C, Vismara LDS, Mazaro SM, Vismara ES, Junior AW. 2018. Frequency of application of salicylic acid and its impact on growth aspects and biochemical quality in lettuce plants (Lactuca sativa L.). Austr J Basic Appl Sci 12 (4): 14-18. DOI: 10.22587/ajbas.2018.12.4.3.

Fehr WR. 1991. Principles of cultivar development. Vol. I. Theory and technique (Volume 1). Macmillian Publishing Company, London.

Gomes EN, Moterle D, Biasi LA, Koehler HS, Kanis LA, Deschamps C. 2018. Plant densities and harvesting times on productive and physiological aspects of Stevia rebaudiana Bertoni grown in southern Brazil. Anais Da Academia Brasileira de Ciencias 90 (4): 3249-3264. DOI: $10.1590 / 0001-3765201820170510$

Johnson HW, Robinson HF, Comstock RE. 1955. Estimates of genetic and environmental variability in soybeans. Agronomy J 47 (7): 314 318. DOI: 10.2134/agronj1955.00021962004700070009x.

Karuniawan A, Maulana H, Anindita PA, Yoel A, Ustari D, Tarkus S, Vergel C. 2021. Storage root yield and sweetness level selection for new honey sweet potato (Ipomoea batatas [L.] Lam). Agriculture 6: 329-345. DOI: $10.1515 /$ opag-2021-0219.

Kendal E. 2019. Comparing durum wheat cultivars by genotype $\times$ yield $\times$ trait and genotype $\times$ trait biplot method. Chilean J Agric Res 79: 512 522. DOI: $10.4067 / \mathrm{S} 0718-58392019000400512$.

Kumar R, Sharma S, Sharma M. 2014. Growth and yield of naturalsweetener plant stevia as affected by pinching. Indian J Plant Physiol 19 (2): 119-126. DOI: 10.1007/s40502-014-0085-8.

Ma Y, Dias MC, Freitas H. 2020. Drought and Salinity stress responses and microbe-induced tolerance in plants. Front Plant Sci 11: 591911. DOI: 10.3389/fpls.2020.591911.

Malek MA, Rafii MY, Afroz MSS, Nath UK, Mondal MMA. 2014. Morphological characterization and assessment of genetic variability, character association, and divergence in soybean mutants. Sci World J 2014: 968796. DOI: 10.1155/2014/968796.

Maulana H, Dewayani S, Solihin MA, Arifin M, Amien S, Karuniawan A. 2020. Yield stability dataset of new orange-fleshed sweet potato (Ipomoea batatas L. (lam)) genotypes in West Java, Indonesia. Data in Brief 32: 106297. DOI: 10.1016/j.dib.2020.106297.

Mohammadi R. 2019. Genotype by yield*trait biplot for genotype evaluation and trait profiles in durum wheat. Cereal Res Commun 47 (3): 541-551. DOI: 10.1556/0806.47.2019.32.

Mustamu YA, Tjintokohadi K, Gruneberg WJ, Karuniawan A, Ruswandi D. 2018. Selection of superior genotype of sweet-potato in Indonesia based on stability and adaptability. Chilean J Agric Res 78 (4): 461469. DOI: 10.4067/S0718-58392018000400461.

Nehe A, Akin B, Sanal T, Evlice AK, Ünsal R, Dinçer N, Demir L, Geren H, Sevim I, Orhan Ş, Yaktubay S, Ezici A, Guzman C, Morgounov A. 2019. Genotype $x$ environment interaction and genetic gain for grain yield and grain quality traits in Turkish spring wheat released between 1964 and 2010. PLoS One 14 (7): e0219432. DOI: 10.1371/journal.pone.0219432.

Pandey G, Prasad R, Prasad B, Chauhan P. 2015. Co-efficient of variation, heritability, genetic advance and variability for rice bean (Vigna umbellata (Thunb.) genotypes under mid-hill conditions of Uttarakhand. J Appl Nat Sci 7 (2): 794-798. DOI: 10.31018/jans.v7i2.685.

Payasi DK. 2015. Genetic variability analysis for seed yield and its components in Mungbean (Vigna radiata L. Wilczek). Int J Plant Breed Genet 9 (3): 177-188. DOI: 10.3923/ijpbg.2015.177.188.

Ruswandi D, Yuwariah Y, Ariyanti M, Syafii M, Nuraini A. 2020. Stability and adaptability of yield among earliness sweet corn hybrids in West Java, Indonesia. Int J Agronom 2020: 4341906 DOI: $10.1155 / 2020 / 4341906$

Sieminska MD, Najda A, Gawronski J, Balant S, Swica K, Zaba A. 2020. Natural sweetener - Biochemical and genetic characterization. Molecules 25 (4): 767. DOI: 10.3390/molecules25040767.

Sudrajat DJ, Suwandhi I, Siregar IZ, Siregar UJ. 2018. Variation in seed morpho-physiological and biochemical traits of Java olive populations originated from Java, Bali, Lombok, and Timor Islands, Indonesia. Biodiversitas 19 (3): 1004-1012. DOI: 10.13057/biodiv/d190332.

Taïbi K, Taïbi F, Ait Abderrahim L, Ennajah A, Belkhodja M, Mulet JM. 2016. Effect of salt stress on growth, chlorophyll content, lipid peroxidation and antioxidant defense systems in Phaseolus vulgaris L. S Afr J Bot 105: 306-312. DOI: 10.1016/j.sajb.2016.03.011.

Ucar E, Ozyigit Y, Eruygur N, Güven D, Yur S, Turgut K, Özek T, Kütük N. 2018. The effect of the plant age and growth period on the nutritional substance, chlorophyll and steviol glycoside rates in stevia (Stevia rebaudiana B.) leaves. Commun Soil Sci Plant Anal 49 (3): 291-302. DOI: 10.1080/00103624.2018.1424894.

Yan W, Frégeau-reid J. 2018. Genotype by yield*trait (GYT) biplot: A novel approach for genotype selection based on multiple traits. Sci Rep 8: 8242. DOI: 10.1038/s41598-018-26688-8.

Yan W, Rajcan I. 2002. Biplot analysis of test sites and trait relations of soybean in Ontario. Crop Sci 42 (1): 11-20. DOI: 10.2135/cropsci2002.1100.

Yeganehpoor F, Salmasi SZ, Kolvanagh JS, Kazeem GG, Dastborhan S. 2016. Changes in growth, chlorophyll content and grain yield of Coriander (Coriandrum sativum L.) in response to water stress, chemical and biological fertilizers and salicylic acid. Int J Adv Biol Biomed Res 5 (1): 228-236. DOI: 10.18869/ijabbr.2016.228.

Zhang J, Bell LN. 2017. Stability of the stevia-derived sweetener rebaudioside a in solution as affected by ultraviolet light exposure. $\mathrm{J}$ Food Sci 82 (4): 897-903. DOI: 10.1111/1750-3841.13667. 